Original paper

\title{
Disaster Information from the Viewpoint of Speech Act Theory: Constative, Performative, and Declarative Utterances
}

\section{Katsuya Yamori ${ }^{1}$}

Received: 02/02/2018 / Accepted: 18/01/2019 / Published online: 25/07/2019

\begin{abstract}
From the viewpoint of speech act theory, this paper discusses recent practical problems pertaining to disaster information and proposes a solution. One of the essential findings in speech act theory is the distinction between constative and performative utterances. A constative utterance (e.g., "this is a pencil") describes an outer world as a normative standard into which the utterance fits. Oppositely, a performative utterance (e.g., "please open the door") describes what is required for an outer world to fit into the utterance. From among the many types of disaster information, we first consider two types: typhoon and tsunami information released by the Japanese Meteorological Agency and evacuation directives/advisories announced by local governments. The typhoon and tsunami information is mostly categorized as constative utterances, and the evacuation directives/advisories are categorized as performative utterances. For disaster reduction, it is critical to make evacuation directives/advisories more powerful and persuasive. However, most recent research has focused on improving the accuracy of meteorological forecasts. Research along these lines has yet to overcome major social problems related to disaster information, such as low evacuation rates and overreliance on disaster information. Declarative utterances (e.g., "I declare the meeting closed") are a third type of utterance: They bridge constative and performative utterances and can serve as a key to solving problems related to disaster information. For example, the "evacuation declaration procedure" has been shown to be effective for safe, early evacuation. In this procedure, local residents themselves, with the assistance of disaster experts, establish a local evacuation criterion in advance. When an emergency approaches, the "evacuation declaration" is issued as soon as the condition is met, prompting residents to evacuate quickly.
\end{abstract}

Key words: disaster information, speech act theory, constative utterance, performative utterance, declarative utterance, evacuation directive/advisory.

\footnotetext{
${ }^{1}$ Disaster Prevention Research Institute, Kyoto University, Institute, Kyoto University. E-mail: momosan@mx5.canvas.ne.jp
} 


\section{INTRODUCTION: FUNDAMENTALS OF SPEECH ACT THEORY}

From the viewpoint of speech act theory, this paper discusses and proposes a solution to recent practical problems pertaining to disaster information. First proposed by Austin (1975) and Searle (1985) and later developed by others, speech act theory is a central theory of pragmatics, which, together with semantics and syntactics, comprises a primary branch of linguistics. Pragmatics focuses on language as it is actually used, studying the relationships between speech, speaker, and context of speech.

For example, let us consider the simple utterance, "Do you know what time it is?" Rather than expecting a response of "Yes, I do," or "No, I don't," the speaker typically expects an answer along the lines of, "It's a little after three." In other words, the phrase typically functions as a demand or request for information about the current time. However, it is also possible to imagine a situation in which it is used literally, and a response such as, "No, I'm sorry, I don't," would not be unnatural.

Thus, if the utterance "Do you know what time it is?" is extracted from its context of use and analyzed purely from a semantic or syntactical perspective, it is not possible to know whether it is functioning literally (as a question) or as an order or request. The relationship between the speakers and the context of speech determines the utterance's function. In such a situation, pragmatics (speech act theory) is essential.

\section{CONSTATIVE AND PERFORMATIVE UTTERANCES}

One of the essential concepts in speech act theory is the distinction between constative and performative utterances. Below, we discuss this distinction in the context of disaster information. However, it should be noted here that, although these two types of utterances can be distinguished theoretically, constative and performative utterances are in actuality cross-cutting and fused with one another, depending both on a context under which utterances are made and on a relationship between those who speak and are spoken. We will be back this critical point later in section 4 and 5.

\subsection{What are constative utterances?}

The primary function of language is typically thought to be description of the surrounding world. In fact, the majority of the linguistic expressions that come to mind as examples of language acquisition, such as "This is a dog," or "That is Tom," are constative utterances.

In constative utterances, the outer world serves as the normative standard that words adapt to and describe. In other words, to achieve consistency between words and reality, words are adapted to match the outside world. We can express this using Searle's (1985) key concept of "direction of fit" as "word-to-world." The image is of words changing to match the normative standard of the outside world in instances where the two are not consistent. For instance, if the speaker sees what s/he believes to be a pencil and says, "That is a pencil," but then learns 
that it is in fact a pencil-shaped piece of chocolate, s/he will change her/his utterance to "That is a pencil-shaped chocolate (not a pencil)," thereby making words consistent with reality.

The majority of disaster information, whether it is a typhoon intensity announcement or information about a predicted tsunami, falls into the category of constative utterances. For example, announcements such as "Typhoon A is currently at location $\mathrm{X}$, and is moving eastnortheast at a speed of $20 \mathrm{~km} / \mathrm{h}$. The central pressure is $960 \mathrm{hPa}$, and the wind speed at the center is over $150 \mathrm{~km} / \mathrm{h}$," "There is a risk of a tsunami measuring $3 \mathrm{~m}$ or lower reaching the Pacific coast of North-Eastern Japan," are constative utterances that objectively describe (or forecast) the current or future condition of the world, regardless of whether they express actual measurements that have already been taken or are a forecast or estimate based on these measurements.

Because these expressions of disaster information are constative utterances, inconsistencies between words and reality are addressed by revising the words (word-toworld). A typical example of this is an announcement such as, "The predicted tsunami height has been revised. The tsunami is predicted to exceed $5 \mathrm{~m}$."

It is precisely this process that has improved the accuracy and speed of disaster information, and has served as a powerful driver to induce disaster related institutions to introduce higher-technology oriented disaster information, particularly in nations with technically more advanced warning systems for natural disaster, such as Japan. For instance, in Japan, meteorological warnings were previously issued for prefectures as a whole, but they are now more finely segmented and issued for individual municipalities (improved accuracy). This is clearly an instance of a mismatch between reality and words (warnings being issued in some municipalities where they were not needed) being resolved through revision of words (warning being issued or not issued as needed).

Additionally, in the recent past, it was only possible to update typhoon information once every few hours, but improvements in measurement and communication technology such as weather satellites now allow this information to be updated in near real time (improved speed). We can interpret this as an effort to resolve a mismatch between words (current typhoon information) and reality (actual typhoon conditions) by revising words (improved speed and frequency of updates) to reduce the mismatch to near zero.

However, a critical problem remains: Are these efforts functioning as intended? Is increased accuracy and speed of disaster information in fact contributing to the ultimate goal of disaster information, which is to reduce the impact of disasters and to save human lives? After describing performative utterances in the following section, we devote the remainder of the paper to discussing this critical issue.

\subsection{What are performative utterances?}

Speech act theorists have indicated that while words certainly describe the world, they also serve other important roles, and that in addition to constative utterances, an entirely separate type of expression also exists, called "performative utterance". 
Orders and requests such as "Please open the window" and the aforementioned "Do you know what time it is?" are typical performative utterances. The essential point here is that performative utterances function in a manner completely opposite from constative utterances. In this case, words are the normative standard, and the world is meant to change to match them. Consistency between reality and words is thus achieved by adapting the world to words. We can express this using Searle's (1985) concept of "direction of fit" as "world-to-word." The image is of altering the world to match the words in instances where the two are not consistent. For example, when the phrase "Please open the window" is spoken, the window, which had until that moment been shut, is opened, thereby ensuring consistency between words and reality by altering the world.

Evacuation directives/advisories, such as "evacuate immediately to a higher ground," and many types of commands/directives made in disaster management, such as "contact with a public information officer and a liaison officer when X happens," specified in Incident Command System (FEMA, 2008), are clearly a quintessential example of performative utterance, and are distinct from the type of disaster information described in the former section. This information (language) functions as a command or request to alter the condition of the world from one in which an evacuation has not taken place to one in which it has. They are linguistic expressions that urge the resolution of a mismatch between words and reality by altering the world (via evacuating).

The same critical problem that exists with disaster information categorized as constative utterances also exists with regard to disaster information categorized as performative utterances: Evacuation directives/advisories often do not function effectively. Examples include the persistence of low evacuation rates even when evacuation orders have been issued (Murakami, Takimoto, and Pomonis, 2012; Sun, Nakai, Yamori, and Hatayama, 2016), and the problems of normalcy bias (Drabek, 2011; Hein, 2014), false alarm effect (Breznitz, 1984; Dow \& Cutter, 1998), and any other human cognitive biases, leading to failure to cope with disasters properly. The following section re-examines this issue taking into consideration both constative and performative utterances.

\section{PROBLEMS OF DISASTER INFORMATION FROM THE VIEWPOINT OF CONSTATIVE AND PERFORMATIVE UTTERANCES}

\subsection{Problems related to constative utterances}

Many of the societal problems related to disaster information, listed above, can be understood from the viewpoint of constative and performative utterances, yielding a new perspective that leads toward new solutions. In this section, we begin by more clearly elucidating the problem.

Let us first consider an example related to constative utterances. It is normally possible, as far as Japanese society is concerned, to release flood warning information (constative utterances) after observing that the water level has reached a prescribed warning level. Likewise, when the river actually flooded, it is possible to release flood information (also 
constative utterances). However, it remains technologically difficult even in Japan with stateof-the-art observation and information warning systems for meteorological disasters (Yamori, 2007; 2013a), to release statements (constative utterances) such as " $\mathrm{X}$ river is predicted to flood at X bridge 2 hours from now" before flooding actually occurs. This is a situation in which the language has not been brought into perfect accord with the actual condition of the world (the condition of $\mathrm{X}$ river at $\mathrm{X}$ bridge 2 hours later); as such, it is clearly a problem related to constative utterance.

Innumerable examples of this type of problem exist, among them the fact that at the present time it is nearly impossible to predict earthquakes. The structure of the problem is simple, and thus the path toward resolving it is clear. In all of these cases, the quality of the constative utterance is (still) poor. The solution therefore lies in bringing words into accord with reality (word-to-world); in other words, it depends upon advances in the natural sciences engaged in describing and predicting the condition of the world. However, the prospects for this are not necessarily optimistic when considering highly uncertain, unpredictable and even chaotic characteristics of natural phenomena.

Furthermore, even if work toward this end proceeds smoothly, another critical problem remains. This is the issue of whether improving the accuracy of constative utterances contributes to the ultimate goal of disaster information, which is to reduce the impact of disasters, and whether those reductions make sense from a cost-performance perspective. Rather than adopting the logic of trying to implement whatever is technically possible, this approach asks whether improvements in disaster information accuracy are being undertaken with a clear awareness that disaster damage reduction is the ultimate goal.

For example, not a few technical or academic words/phrases spread widely in Japanese society, which had not been familiar to the general public, every time after natural disasters, such as, "a back-building effect contributing to extraordinarily rapid and continuous development of cumulonimbus" or "asperity areas causing unexpectedly huge quakes and tsunami." Such newly introduced words/phrases to everyday world in the aftermath of disasters, not prior to those, jeopardize people's trust on knowledge and findings in disaster related sciences. People are more likely to feel that disaster sciences give us many after-thefact explanations to specify what happened, but, frequently failed to provide prior information usable to prevent and reduce disaster damages. This pattern arises from the fact that it is impossible to release constative utterances in advance of the alterations in the real world that they seek to describe, and thus it is only after an incident occurs that these statements are released.

Because constative utterances resolve discord between words and reality by altering words, they have the inherent quality of playing catch-up. It is precisely because descriptions of reality are often revealed to be inadequate that steps are taken after the fact to revise or replace the words that comprise them (explanations). In that sense, the type of criticism noted above could be seen as the inevitable fate of constative utterance mainly produced by natural sciences. 
However, within the field of disaster information research, it is essential to pay attention to this type of popular dissatisfaction of the public. It is important for researchers to ask whether the conventional response to repeated disasters, improving constative utterances to make them more accurate and timely, might be fundamentally misguided. Have we in fact been right to focus so single-mindedly on the improvement of constative utterances (which is of course necessary in many ways), while putting aside improvement of the performative utterances that, from a damage reduction perspective, ought fundamentally to be the priority of disaster information research, but which instead we have baselessly assumed will somehow work themselves out?

\subsection{Problems associated with performative utterance}

Next, let us examine the problems associated with performative utterances. The most significant of these is the simple but acute problem of few people evacuating despite an evacuation directive/advisory (performative utterance) having been issued (see for example Murakami, et.al, 2012; Fraser, Leonard, Matsuo, and Murakami, 2012; Yamori, 2013b; Sun, et.al.,2016). This signifies very clearly that the performative utterance (the order or request) is not functioning.

It is necessary here to clarify the standard by which evacuation directives/advisories should be evaluated. Because these are performative utterances, they must be evaluated purely on the basis of whether the state of reality they seek to achieve (people evacuating) has been realized. In actuality, however, that standard is frequently not used. Evacuation directives/advisories tend to be evaluated in Japan not on the basis of whether they were carried out, but instead on whether they were issued. In other words, society tends to ask whether the condition (itself expressed as a constative utterance) of having issued an evacuation advisory or directive has been realized.

To make matters worse, local governments, in charge of issuing evacuation directives/advisories in Japan, react to this reality by hastily issuing directives/advisories in an attempt to avoid criticism for not issuing them; the result is that a string of directives/advisories have been issued that are so broad as to call into question their practical effectiveness. For example, during Typhoon Phanfone in 2014 (which made landfall on October 6th of that year), evacuation directives/advisories targeted 3.6 million people nationwide (a total of 6 people died) (Cabinet Office, 2014). When Typhoon Vongfong arrived approximately one week later (touching down on October 13, 2014), evacuation directives/advisories targeted 1.8 million people nationwide (3 people died) (Fire and Disaster Management Agency Disaster Response Office, 2014). However, actual evacuation rates at officially designated shelters were only less than $1 \%$ in both cases.

A second problem is that since evacuation directives/advisories must be evaluated on the basis of whether the state of reality they seek to achieve has been realized, subsequent events (for instance, whether a nearby river does in fact flood, and whether that flood causes damage) are not immediately relevant to the question of the performative utterance's success or failure. In just the same way, the success of a performative utterance such as "Please open 
the window" is judged based solely on whether the window is opened, and questions such as whether the air circulation improved, or the room temperature fell or rose afterwards are not immediately relevant. It is incorrect to say that there is no relation whatsoever between the success or failure of an evacuation directive/advisory and subsequent events. However, judging from the stubborn societal focus on false alarms and overlooked disasters in Japan, evacuation directives/advisories are evaluated more on the basis of subsequent events than on what should be the main evaluation criterion: whether they caused people to evacuate.

In addition to these issues, an even more fundamental problem exists regarding evacuation directives/advisories as performative utterances. To repeat the point made above, our focus ought to be on the effectiveness of performative utterances (evacuation directives/advisories). However, most of the proposals for improving effectiveness, in Japanese society, put forth thus far do not deal with improving performative utterances, but rather with improving the accuracy of the constative utterances that do no more than provide the factual basis for performative utterances. The situation has moved even further in an undesirable direction in recent years with attempts to eliminate performative utterances altogether; there has been a growing tendency to try to solve the problem by reducing all performative utterances to constative utterances, or more accurately, to create the appearance of having solved the problem.

The former problem (that of efforts to improve the accuracy of constative utterances being substituted for efforts to improve the effectiveness of performative utterances) has already been addressed above, so we will focus here on the latter issue. This relates to "the establishment of specific, mostly numerical, criteria for issuing evacuation directives/advisories (Fire and Disaster Management Agency, 2014). "Specific criteria" here refers to numerical values such as water levels, amounts of rain, or inundation conditions, as well as objective realities such as official warnings issued by different, mostly higher level, governmental organizations (Fire and Disaster Management Agency, 2014). In effect, this means criteria such as, "If the water level of river $\mathrm{X}$ reaches $\mathrm{x}$ meters at $\mathrm{x}$ observation point, an evacuation directive will be automatically and unconditionally issued."

The introduction to the Fire and Disaster Management Agency report quoted above notes that all local governments have called for the establishment of specific criteria for issuing evacuation directives/advisories, and in fact, these efforts have garnered almost universally positive evaluations, such as that they will "eliminate fluctuations in standards arising from changes in local government staff or other factors" and "staff will no longer hesitate to issue directives/advisories from the fear of false alarm effect" (Sankei Shimbun, 2014).

However, speech act theory provides a different perspective. Establishing objective criteria for issuing an evacuation order is an attempt to reduce evacuation directives/advisories, which are inherently performative utterances, to constative utterances. This is because information such as the water level at an observation point is expressible through constative utterances, and the establishment of objective criteria makes evacuation directives/advisories equivalent to this type of objective information. If this approach were to be fully adopted, human (staff) decisions would become completely unnecessary, provided 
the water level data (constative utterance) were available. Of course, some people see this as a positive development.

By contrast, performative utterances by their nature make words the starting point (normative standard), and alter the world to bring it into closer alignment with those words (world-to-word). When performative utterances function meaningfully, the situation is structured so that it is impossible to trace the basis for the order or request further back than the performative utterance (or person who issued it) itself. Osawa (2014a; 2014b) explains this concept via the easily understood example of God's order (prohibition) to Adam and Eve not to eat the apple of the Tree of Knowledge. There is no basis for this order beyond the performative utterance itself. If a basis for this order existed that could be expressed through a constative utterance, such as "the apple is bad for you" or "apples are so delicious there's a risk you'll become addicted to them," and if all aspects of the order (prohibition) were captured by this constative utterance, it would cease to be an order (performative utterance) from God.

Taking the above points into consideration, we see that while expressing the basis for an evacuation directive or advisory as an objective criterion at first appears to strengthen the performative utterance, but, in actuality, it can also be seen as undermining the performative utterance's fundamental nature, which ultimately is to alter the world purely on the basis of the words contained in the utterance (world-to-word). The remainder of this paper proposes, in opposition to conventional wisdom, that if our goal is the mid- to long-term strengthening of evacuation directive/advisory effectiveness, then it is important to leave room for independent decision-making by the person or people issuing the directive/advisory (the local governor or municipal government staff in charge of disaster management, in a Japanese context).

\section{A PRACTICAL PROPOSAL: THE POTENTIAL OF DECLARATIVE UTTERANCES}

Thus far this paper has examined a number of practical problems of disaster information from the perspective of the distinction within speech act theory between constative and performative utterances. Taking that discussion into consideration, this section lays out a practical, pragmatic proposal aimed at resolving these issues. An important premise for this proposal is that when considering performative utterances (evacuation directives/advisories), not only the issuing side (orderer) but also the receiving side (ordered) must be considered. As discussed below, the terms "issuing side/receiving side" and "orderer/ordered," in a dichotomic way of thinking, are themselves problematic. However, in conforming to these terms for the time being, let us note the importance of focusing on the relationship between the two sides.

Why? It is useful here to recall a point introduced in the first section. That is, it is not possible to determine whether or not a phrase such as "Do you know what time it is?" is 
functioning as a performative utterance simply by analyzing it from a semantic or syntactical perspective, in isolation from the context of speech. The relationship between the speakers and the context of the speech determine its function. Likewise, the context of speech and the relationship between orderer and ordered are important in the case of evacuation directives and advisories. In other words, the third type of utterance introduced in the next section, called a declarative utterance, aims at getting out from a primary framework, simply contrasting "word-to-world" and "world to word" types of utterances, but, taking more complex and critical factors into consideration, such as, a context under which utterances are made and a relationship between those who speak and are spoken.

\subsection{What are declarative utterances?}

Just as speech act theory provides important insight into the deeper layers of practical problems in disaster information, it also provides a key for resolving those problems: the special type of expression known as a declarative utterance. Declarative utterances fall between performative and constative utterances. To borrow Osawa's (2014a) phrasing, declarative utterances are obtained when the strength of the command (pressure to perform) in a performative utterance is reduced as close as possible to zero. They are performative utterances that appear almost identical to constative utterances.

A typical example of a declarative utterance is the statement, "I declare the meeting closed." It is immediately apparent that the declarative utterance combines the characteristics of a constative utterance (word-to-world) and a performative utterance (world-to-word). Regarding the former, experience tells us that by the time someone such as the meeting chair announces, "I declare the meeting closed," it is in fact nearly over already. The condition those words seek to describe is almost complete, so the words express a given. Even without saying the meeting is over, it is ending, and this is precisely why it is possible to say, "I declare the meeting closed." This demonstrates that declarative utterances share characteristics with constative utterance.

They also contain elements of performative utterances. Regardless of the point made above, the fact is that if the meeting chair did not say, "I declare the meeting closed," and if everyone did not think, "Meetings are not over until the chair says they're over," then the meeting would not be completely over (although some meetings certainly do dissolve informally as business comes to a close). In other words, the phrase "I declare the meeting closed" does, without question, cause a change in the world (the end of the meeting). Now and then instances even occur in which meeting participants check with the chair before leaving even though the meeting is clearly over, for example by saying "Mr. Chairman, can you declare the meeting over? It's over, right?" The fact that people seek confirmation in this way is an indication that the phrase "I declare the meeting closed" contains elements that cannot be fully reduced to a constative utterance. This demonstrates that declarative utterances include elements of performative utterances.

To connect this point to the discussion at the end of the former section, the statement (by the chair), "I declare the meeting closed" contains the force of an order, albeit a faint one, which cannot be traced to a source other than the speaker (the same element present in God's 
command not to eat the apple). In other words, the language in this statement serves as a normative standard that the world must conform to by changing (world-to-word). Declarative utterances are therefore ultimately performative utterances. However, under ordinary circumstances, the words hold no power unless the meeting is virtually over already ("ordinary circumstances" here excludes exceptional cases such as when the chair unexpectedly leaving or abruptly ending the meeting). The declarative utterance thus also has the character of a constative utterance in that it merely describes the world as it already exists.

\subsection{The evacuation declaration procedure}

In recent years, in Japan, the "evacuation declaration procedure" has been attracting attention for its effectiveness, and related projects are starting to emerge. Our discussion of declarative utterances, in particular their position as a bridge that links performative and constative utterances, allows us to theoretically position the efficacy of the evacuation declaration procedure.

In this procedure, the people who will ultimately evacuate in the event of a disaster (for instance, the residents of a particular district), with the assistance of outside disaster experts, establish a local evacuation criterion in advance, without relying completely on disaster information provided from outside, such as Japanese Meteorological Agency and local government. When a disaster approaches and the previously established criterion is met, the residents issue declarative utterances on their own initiatives, such as " $\mathrm{X}$ district is now in a state of emergency" or "We are now sharing evacuation information for X district," prompting them to evacuate.

In the town of Minakami, located in the mountains of Gunma Prefecture in Japan, Katada and Kanai (2010) are carrying out an action research to establish a resident-led evacuation system in response to landslides. In this system, people in the local community all serve as a "danger detector." Local residents identify dangerous sites (dangerous phenomena) in advance based on guidance from experts, and monitor these sites. They report their observations to the community disaster management leader, who informs residents when the aggregate of the individual reports fulfills certain criteria jointly established in advance, and recommends voluntary evacuation. Residents then evacuate, spreading the message to one another.

The Community Weather Information Project organized by Takenouchi, Kawata, Nakanishi, and Yamori (2014) is another representative example of the evacuation declaration procedure. In this initiative, residents of Tsujikuru District, on the banks of the Miyagawa River in the city of Ise, Mie Prefecture, Japan, worked with experts to establish a range of disaster criteria, including conventional disaster information from outside public organizations as well as direct observations by residents of local conditions, such as the level of the Miyagawa River rising until it reaches the orange line on the pillar of a bridge in the community. Based on these criteria and with the guidance of experts, but ultimately using their own judgment, residents share their own declaration stating, "We are now sharing information for the residents of Tsujikuru to prepare for a flood." The information is also 
disseminated through an emergency contact network, and residents take action by beginning to prepare for evacuation.

It is easy to see that these procedures have the characteristics of a declarative utterance: in the project by Katada and Kanai (2010) and Takenouchi et al. (2014), residents actually evacuate or prepare for evacuation, after declaring and sharing local messages to urge or to encourage neighbors to do so, based on the criteria preset on their own. In these projects, the conditions in the district (condition of the world) are not only reflected in a constative utterance (word-to-world), but also disseminate to the entire local community, including the speaker himself, as a performative utterance (world-to-word).

A closer examination reveals that the evacuation declaration procedure contains characteristics of both constative and performative utterances. The key point here is that no matter what the standards are for issuing the declarative utterance, the people who determine them are the same people who will issue the utterance. In the above example of a meeting, the statement "I declare the meeting closed" functions as a declarative utterance because it is issued within the context of the other meeting participants feeling that the meeting is indeed about to end. Similarly with the evacuation declaration procedure, and ultimately with conventional evacuation directives/advisories as well, it is of life-and-death importance that the people who will actually evacuate share a "sense" in advance that an evacuation directive is imminent.

In this sense, the most significant aspect of the evacuation declaration procedure is the fact that the people who will issue the declaration (who are also the people who will receive it) participate in establishing the criteria. Although experts contribute advice, the people who will issue the declaration make the final decision on which specific local conditions or what conventional disaster information are to be used for their standards. From a different perspective, by introducing a declarative utterance (equal to a zero-degree performative utterance), the evacuation declaration procedure sublates or overcomes the problematic dichotomous way of thinking; a confrontation between issuer (orderer) and receiver (ordered) (Yamori, 2009; 2013b).

In the projects of both Katada and Kanai (2010) and Takenouchi et al. (2014), determining the content of the declarative utterances and carrying out drills based upon them took a number of years and included repeated presentations, workshops, and surveys in the local communities. This suggests that creating a functional declarative utterance cannot be accomplished at a single event during which a declaration is simply written down on paper, but rather requires significant time and effort to change relationships and create the context in which a shared "sense" of imminent evacuation can arise. Only through this process can a situation be created in which declarations ("I declare the meeting closed," "Evacuation will now begin") are issued at a point in time when people already feel them to be imminent.

\section{THE CROSS-CUTTING AND FUSED NATURE OF CONSTATIVE AND PERFORMATIVE UTTERANCES}


We conclude by returning to a point raised in the first section in order to supplement our discussion of issues not adequately developed above. That is, the fact that constative and performative utterances are in actuality cross-cutting and fused with one another.

As Austin (1975) suggested, all speech contains both constative and performative characteristics. Through our statements, we both carry out 'locutionary acts,' that is, we construct and express grammatical utterances from words with fixed meanings, and simultaneously perform 'illocutionary acts' in which we exercise a type of power (illocutionary force) over the listener. These statements can furthermore function as 'perlocutionary acts,' or acts which influence the listener. 'Speech acts' are the composite of these various acts.

For example, the utterance "This room is cold, isn't it" is in formal terms constative, and in many instances is likely to be constative in reality as well. However, it is clear that if this utterance is spoken in a certain type of context between parties with a certain relationship, it can clearly also function on its own as a performative utterance meaning "Please close the window." In this case, while the speaker is performing the locutionary act of saying "This room is cold, isn't it?" she or he is also performing the illocutionary act of exercising power over the listener by instructing him or her to "Close the window." Furthermore, the speaker is also performing a perlocutionary act in that the statement actually influences the listener.

Taking this point into consideration, it is clearly impossible to hastily determine whether a statement such as that given in Section 2.1, "Typhoon A is currently at location X...," is a constative utterance based solely on its form. This is why we noted there that such is the case "in principal or in formal terms." In other words, speech that takes the form of a constative utterance of course also functions in some cases as a performative utterance, such as when that utterance urges the listener to be on alert for a typhoon or to evacuate early.

Thus, from the perspective of speech act theory, we must acknowledge that constative utterances and performative utterances are in fact cross-cutting and fused with one another. In actuality as well, many people involved with typhoon information like that mentioned above (such as employees of the Japan Meteorological Agency and local governments as well as ordinary citizens) do not think of such speech simply as constative utterances; to some degree or another, they likely are aware that it also functions as performative utterances.

However, even though these two types of utterances are functionally intermingled or fused, the spell cast by the fact that a certain speech act is a constative utterance is significant, as pointed out in Section 3.1. It is crucial to once again point out the tendency to insist that the inadequate functionality of constative utterances can be resolved by improving their accuracy. In this sense, researchers will need to focus in the future on finding concrete methods for heightening the performative nature of disaster information presented as (formally) constative utterances, while also acknowledging on a theoretical level that disaster information which in formal terms is constative can also, in functional terms, be performative. 
Let us consider an example. Yamori (2016) mentions the particular effects of disaster information that incorporates proper nouns, such as "heavy rains as severe as those that hit the Tokai region in 2000." Leaving aside the pros and cons of individual cases, this type of disaster information constitutes a constative utterance in formal terms because it simply indicates a particular phenomenon (such as the state of current rains) by using a specific name. However, such speech can have far greater performative force (power to encourage evacuation) than formal performative utterances such as "Please evacuate immediately," not to mention constative utterances that give more detailed information about the phenomenon in question, such as "X mm of rain is falling per hour" or "XX River has reached dangerous levels." While this example demonstrates the great potential of disaster information presented as constative utterances, it also suggests that we cannot expect much improvement in the impact of such information simply by following the conventional approach of communicating it "faster, more accurately, and in greater detail".

The same can be said of performative utterances. That is, there is no guarantee that formal performative utterances, typically, speech (utterances) that incorporates performative verbs, such as "order" or "direct," will always successfully comprise illocutionary or perlocutionary acts. This has already been pointed out in Section 3.2. When this is the case, one solution that immediately comes to mind is to strengthen the pressure to act. In examples from the field of disaster information studies that have attracted attention in recent years, this corresponds to altering the content or tone of performative utterances in order to strengthen their performative nature (i.e., using an authoritative tone), for instance by saying "Evacuate immediately!" rather than "Please evacuate."

Some studies have reported a degree of success from using this method in locations such as Oarai, Ibaraki Prefecture, during the Great East Japan Earthquake (Inoue, 2012). Lessons from this experience were later applied to improve calls for action during emergency reports by the broadcaster NHK (Fukunaga, 2013). However, some caution must be exercised in assessing this approach, as the results did not depend entirely on the style or tone of the utterance. In our consideration of declarative approaches in Section 4, we pointed out that in order for declarative utterances to be effective, it is essential to create an appropriate context. In the present section, too, we have noted that "if it is spoken in a certain type of context between parties with a certain relationship," even a constative utterance can very easily produce the effects of a performative utterance.

Taking this point into consideration, it becomes clear that appropriate context and relationships are equally important if attempts to use authoritative tone to improve performative utterances are to be effective. Although it is only one example, in the case of the NHK announcers, authoritative tones were rarely used in ordinary broadcasts, and this fact likely provided important context for the effectiveness of the emergency broadcasts. In other words, what truly deserves attention is not the use of an authoritative tone, but rather the fact that such a tone was not used in ordinary situations.

Furthermore, in the case of Oarai (Inoue, 2012), it was not only the authoritative tone itself that proved effective, but also the fact that specific names of districts within Oarai (proper 
nouns) were used when calling for evacuation, and the fact that calls for evacuation were issued from the city office (listeners likely believed), not somewhere far from the danger of the tsunami, such as a broadcasting studio in Tokyo. The calls to evacuate were issued in an authoritative tone by someone who, listeners likely believed, faced the same risks that they did. This context and set of relationships came together to strengthen the performative force of the utterance "Evacuate immediately" spoken in an authoritative tone.

In this way, speech act theory enables us to view disaster information not as information describing the condition of the world (typically, the state of hazards), but rather in terms of the effects of communication acts produced by all interactions concerning that information. From this perspective, it is clear that without a fundamental transformation of context and relationships, in other words, without probing the tangle of problems lying between constative and performative utterances and looking directly at issues pertaining to relationships between the individuals issuing performative utterances and those receiving them, but instead simply improving the accuracy and propagation speed of constative utterances, reducing performative utterances (evacuation directives/advisories) to constative utterances, and also adopting tones and styles that at first glance appear to unconditionally strengthen performative utterances, we will not be able to produce truly effective disaster information.

This perspective and type of analysis is unlikely to be attained solely by engaging with practical problems on the ground. On-the-ground engagement is of course important and must be emphasized as the starting point for all research into disaster information. However, the truly meaningful, radical (or fundamental) prescriptions needed to transform reality in many cases become clear only when theoretical or conceptual frameworks are added.

It is our hope that the present study will contribute in some small way to this effort.

\section{REFERENCES}

Austin, J. L. (1975) How to do things with words (2nd ed.). Oxford University Press, Oxford, England

Breznitz, S. (1984) Cry wolf: The psychology of false alarms. Lawrence Erlbaum Associations, Inc, Hillsdale, New Jersey.

Cabinet Office (2014) 2014 Taifu dai 18 gou niyoru oame tou niyoru higai jokyo tou nitsuite, [Damage from heavy rains caused by Typhoon No.18.] http://www.bousai.go.jp/updates h26typhoon18/pdf/h26typhoon18_11.pdf. [Japanese] Accessed 15 January 2018.

Dow, K. and Cutter, S. L. (1998) Crying wolf: Repeat responses to hurricane evacuation orders. Coastal Management, 26 (4): 237-252.

Drabek, T. E. (2011) Human system responses to disaster: An inventory of sociological findings (Springer Series on Environmental Management). Springer, New York. 
FEMA (2008) ICS Review Material. FEMA.

https://training.fema.gov/emiweb/is/icsresource/assets/reviewmaterials.pdf. Accessed 6 December 2018.

Fire and Disaster Management Agency (2014) Hinan kankoku tou ni kakaru gutaiteki na hatsurei kijun no sakutei jokyo tou chosa kekka. [Status report on establishing criteria for evacuation directives/advisories.]

http://www.fdma.go.jp/neuter/topics/houdou/h26/2604/260408_1houdou/01_houdoushiryo u.pdf.[Japanese] Accessed 15 January 2018.

Fire and Disaster Management Agency Disaster Response Office (2014) Taifu dai 19 gou ni tomonau oame boufu tou niyoru higai jokyo tou nitsuite (dai 11 pou). [Damage from heavy rains and wind caused by Typhoon No. 19 (\#11).]

http://www.fdma.go.jp/bn/\%E3\%80\%90\%E7\%AC\%AC11\%E5\%A0\%B1\%E3\%80\%91\% Е5\%8F\%B0\%Е9\%A2\%A8\%Е7\%AC\%AC19\%Е5\%8F\%B7\%Е7\%AD\%89\%Е3\%81\%AB $\%$ Е4\%ВC\%B4\%Е3\%81\%86\%Е8\%A2\%AB\%Е5\%AE\%B3\%Е7\%8А\%В6\%Е6\%В3\%81 $\%$ E7\%AD\%89\%E3\%81\%AB\%E3\%81\%A4\%E3\%81\%84\%E3\%81\%A6.pdf. [Japanese] Accessed 15 January 2018.

Fraser, S., Leonard, G.S., Matsuo, I., and Murakami, H. (2012) Tsunami evacuation: Lessons from the Great East Japan earthquake and tsunami of March 11th 2011, GNS Science Report 2012/17. http://crew.org/sites/default/files/SR\%202012-017.pdf. Accessed 15 January 2018.

Fukunaga, H. (2013) Tsunami keihou: NHK ga tsuyoi kuchou de hinan yobikake. [Tsunami warning by using an authoritative tone in NHK broadcasting.] Hoso kenkyu to chosa, 63(2): 76. [Japanese].

Hein, P. (2014) Expecting the unexpected: A case study on tsunami mitigation in Fujisawa (Japan), Environmental Hazards, 13 (1): 1-20.

Inoue, H. (2012) Meirei cho wo tsukatta tsunami hinan no yobikake [Calling for evacuation from tsunami in an authoritative tone.] Hoso kenkyu to chosa, 62 (3), pp.22-31. [Japanese].

Katada, T. and Kanai, M. (2010) Dosha saigai wo taishou tosita jumin shudougata hinantaisei no kakuritsu no tameno komyunikeishon dezain. [Resident-led communication design to establish independent evacuation local rules for landslides]. Collected Papers on the Practice of Civil Engineering, 1: 106-121. [Japanese]

Murakami, H, Takimoto, K. and Pomonis, A. (2012) Tsunami evacuation process and human loss distribution in the 2011 Great East Japan Earthquake --- A case study of Natori City, Miyagi Prefecture. Paper presented at the 15th World Conference on Earthquake Engineering, Lisbon, Portugal. http://www.iitk.ac.in/nicee/wcee/article/WCEE2012_1587.pdf . Accessed 15 January 2018.

Osawa, M. (2014a) Jumon no gotoki sengen bun. [Declarative utterances like magic spells.] Hon, June 2014: 54-61. [Japanese]

Osawa, M. (2014b) Genteki hiteisei. [The original negativity.]) Hon, July 2014: 54-61. [Japanese]

Sankei Shimbun (2014) Konnan na hndan: jchitai niyoru hinana shiji to kankoku. [Difficult judgement: Evacuation directives/advisories issued by local government in Japan.]. 
September 6, 2014. http://www.sankei.com/west/print/140906/wst1409060027-c.html. [Japanese] Accessed 15 January 2018.

Searle, J.R. (1985) Expression and meaning: Studies in the theory of speech acts. Cambridge University Press, Cambridge, England.

Sun. Y., Nakai, F., Yamori, K., and Hatayama, M. (2016) Tsunami evacuation behavior of coastal residents in Kochi Prefecture during the 2014 Iyonada Earthquake. Natural Hazards, 85: 283-299. (doi:10.1007/s11069-016-2562-z).

Takenouchi, K., Kawata, Y., Nakanishi, C., and Yamori, K. (2014) Collaboration on local weather information between weather forecasters and weather information users. Journal of Natural Disaster Science, 35: 67-80.

Yamori, K. (2007) Disaster risk sense in Japan and gaming approach to risk communication. International Journal of Mass Emergencies and Disasters, 25: 101-131.

Yamori, K. (2009) Bosai ningen kagaku [Human science of disaster mitigation.] University of Tokyo Press, Tokyo, Japan. [Japanese]

Yamori, K. (2013a) A historical overview of earthquake perception in Japan: Fatalism, social reform, scientific control, and collaborative risk management. (In) T, Rossetto, H, Joffe, and J, Adams (eds.). Cities at risk: Living with perils in the 21st century. Springer Verlag, Dordrecht: $73-91$.

Yamori, K. (2013b) Kyodai saigai no risuku komyunikeishon: Saigai joho no atarashii katachi. [Improving disaster risk communication: A paradigm shift in disaster information research.] Minerva Shobo, Kyoto, Japan. [Japanese]

Yamori, K. (2016) Koyu meishi toiu saigai joho. [Using proper nouns more effectively in disaster information.] News letter of Japanese Society for Disaster Information Studies, 61: 1. [Japanese] 